\title{
Vestibulotomy in Congenital Stapes Fixation with Anomalous Facial Nerve
}

\author{
Hwan Kim ${ }^{1}$, Jin Won Kim, Dong Chul Cha ${ }^{1}$, and Hyun Seung Choi ${ }^{2}$ \\ ${ }^{1}$ Department of Otorhinolaryngology, Yonsei University College of Medicine, Seoul; and \\ ${ }^{2}$ Department of Otorhinolaryngology-Head and Neck Surgery, National Health Insurance Service Ilsan Hospital, Goyang, Korea
}

\section{안면신경 기형을 동반한 선천성 등골고정에서의 전정 절개술}

김 환 $^{1} \cdot$ 김진원 ${ }^{1} \cdot$ 차동철 ${ }^{1} \cdot$ 최현승 $^{2}$

연세대학교 의과대학 이비인후과학교실, ${ }^{1}$ 국민건강보험 일산병원 이비인후과 ${ }^{2}$

\author{
Received October 5, 2015 \\ Revised December 15, 2015 \\ Accepted January 4, 2016 \\ Address for correspondence \\ Hyun Seung Choi, MD \\ Department of Otorhinolaryngology- \\ Head and Neck Surgery, \\ National Health Insurance \\ Service Ilsan Hospital, \\ 100 Ilsan-ro, Ilsandong-gu, \\ Goyang 10444, Korea \\ Tel +82-31-900-0972 \\ Fax +82-31-900-0613 \\ E-mail choihyunseung@gmail.com
}

Conductive hearing loss is a condition that can be corrected surgically in most cases. Stapedotomy is usually performed for patients with congenital ossicular anomaly or fixation. However, otologic surgeons have often encountered difficulty due to the complexity of stapes surgery. Moreover, congenital stapes fixation with anomalous facial nerve and oval window absence is an uncommon and dangerous condition. In such cases, vestibulotomy can be a surgical option to prevent facial nerve damage and improve hearing. The etiology can be explained by the embryological development of the middle ear structures. To prevent facial nerve damage and maximize the efficacy of surgery, the surgeon should have knowledge about this disease and take a computed tomography for double check before stapes surgery. We describe a case of congenital stapes fixation with aberrant facial nerve courses, a 15-yearold female who was treated with vestibulotomy and piston wire insertion.

Korean J Otorhinolaryngol-Head Neck Surg 2016;59(6):471-4

Key Words Facial nerve $\cdot$ Hearing loss, conductive $\cdot$ Oval window, ear · Vestibulotomy.
서 론

전음성 난청은 외과적 수술로 물리적인 소리전달 과정을 회복시켜 환자의 청력을 개선할 수 있는 이과 분야의 대표적 질환이다. 그러나 등골(stapes)의 고정으로 인한 전음성 난청 의 경우 수술의 복잡성 및 부작용 발생 가능성으로 인해 외 과적 치료가 최근에야 확립되었다.

1952년 Rosen이 처음으로 등골가동술(mobilization)을 통 해 성공적인 청력 회복을 이룬 이후 현대적인 등골수술이 시 작되었는데 ${ }^{1)}$ 기본 원칙은 등골고정을 해소하면서 피스톤 고 리(piston wire)를 침골(incus)에 연결하여 소리 전도성을 향 상시켜 청력개선을 도모하는 것이다.

드물게 선천성 등골고정 환자에서 안면신경의 고실분절이 이상 주행을 하여 난원창 및 등골의 기형을 유발할 수 있는
데, 이는 발생학적으로 안면신경과 이소골의 발생 기원 및 시 기의 유사성으로 인한 것으로 보인다.,3) 이러한 선천성 등골 고정 환자의 등골수술에 있어 안면신경(facial nerve)이 난원 창(oval window)을 덮고 있거나, 이상 주행을 할 경우, 개창 술의 시행부위를 결정하고, 안면신경 손상 없이 수술을 하는 것은 어렵다. 저자들은 안면신경의 이상 주행 및 난원창의 결손을 동반한 선천성 등골고정 환자에서 전정 절개술(vestibulotomy)을 시행하여 성공적으로 청력개선을 한 1예를 보 고하고자 한다.

\section{증 례}

특이 과거력 없는 15 세 여환이 어릴 적부터 지속된 좌측 전 음성 난청을 주소로 내원하였다. 이전 감염이나 외상의 과거 
력은 없었으며 이학적 검사상 양측 고막 및 외이도의 이상 소견은 보이지 않았다. 순음검사결과 좌측의 $50 \mathrm{~dB}$ 의 기도 골도차(air-bone gap)가 관찰되었다(Fig. 1A). 수술 전 촬영 한 측두골 전산화단층촬영상 양측 안면신경의 고실분절 (tympanic segment of facial nerve)이 등골(stapes)의 내측 하방(inferomedial)으로 주행하였고, 등골(stapes)의 기형 (deformity)이 확인되었으며 난원창은 관찰되지 않았다(Fig. 2). 선천성 등골고정 및 안면신경의 기형(congenital stapedial fixation with anomalous facial nerve) 의심하에 전신마 취하 시험적 고실개방술(explo-tympanotomy)을 시행하였 다. 외이도가 협소하여 경외이도 접근(transcanal approach) 이 불리하여 후이개접근법(retroauricular approach)으로 고 실을 노출 후 큐렛(curette)으로 골부 외이도를 넓혀 시야를 확보하였다. 이소골 중 추골(malleus)과 침골(incus)은 정상
적으로 관찰되었으나, 등골(stapes)의 상부구조(suprastructure)는 왜소한 크기의 직선형 모형으로 기형을 보였고, 등골 족판(footplate)은 고정되어 있었다. 안면신경의 이상 주행으 로 난원창이 정상적으로 관찰되지 않았으며 안면신경 상부 에 절흔의 형태가 관찰되었다(Fig. 3A). 침골 및 등골 상부구 조를 분리하고 등골 상부구조를 제거하였다. 천공기(perforator)를 이용하여 안면신경 고실 분절 위의 절흔을 통하여 골부 전정에 구멍을 딿고, $6 \mathrm{~mm}$ 피스톤(piston wire)을 삽입 하였으며, 피스톤의 고리는 침골의 장돌기(long process of the incus)에 걸어, 안면신경의 손상 없이 전정 절개술을 시 행하였다(Fig. 3B). 수술 후 어지럼증, 안면신경 마비, 미각 소실 등의 합병증은 없었다. 수술 1년 후 시행한 순음검사결 과 기도골도차가 $5 \mathrm{~dB}$ 로 줄었으며(Fig. 1B), 현재 특이 합병 증 없이 외래 경과관찰 중이다.
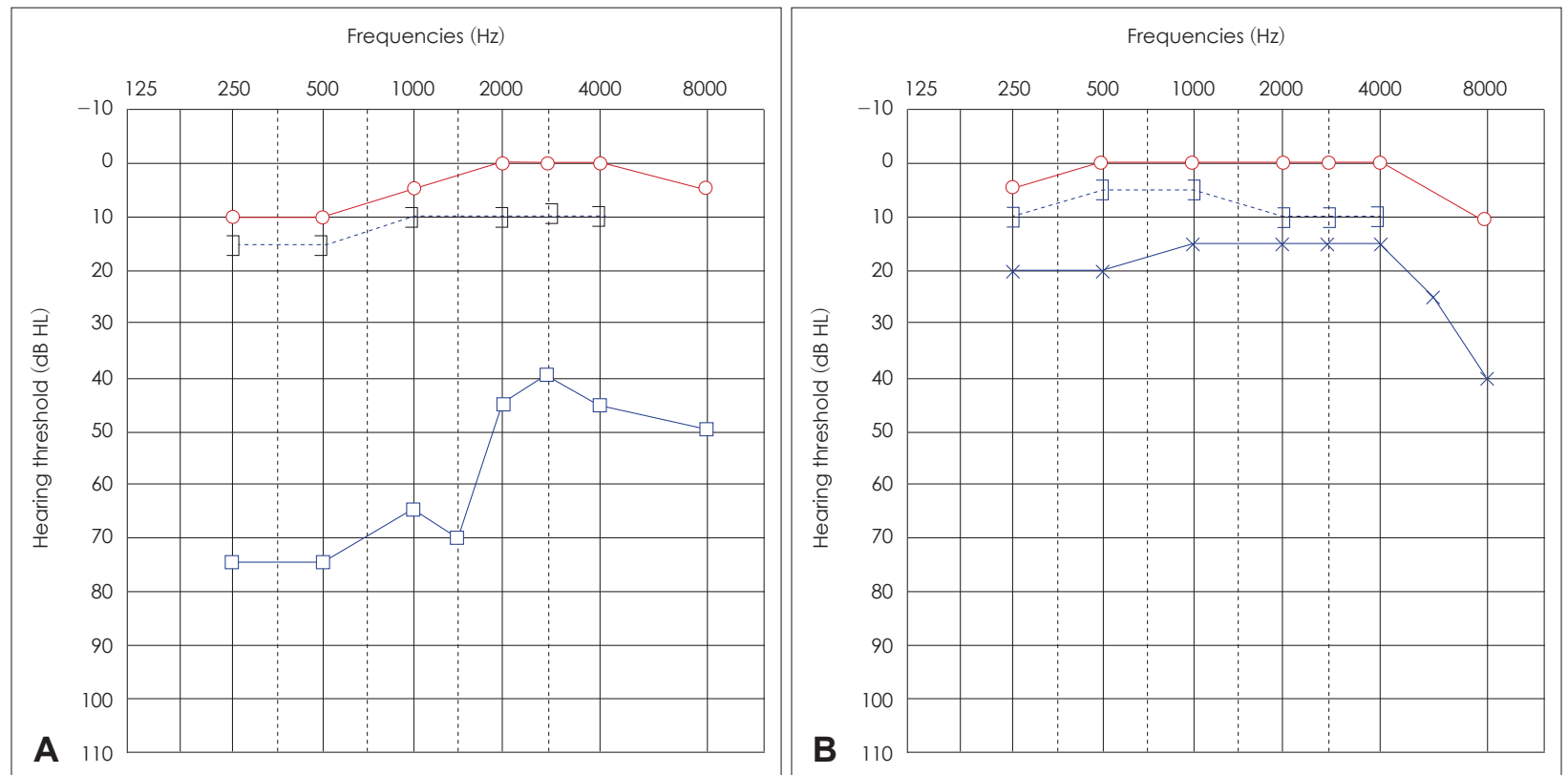

Fig. 1. Preoperative pure-tone audiogram (A). Patient showed $50 \mathrm{~dB}$ hearing threshold on her left ear and the hearing loss was caused by conductive cause. Postoperative pure-tone audiogram (B). Left hearing function was markedly improved and air-bone gap was decreased up to $5 \mathrm{~dB}$.
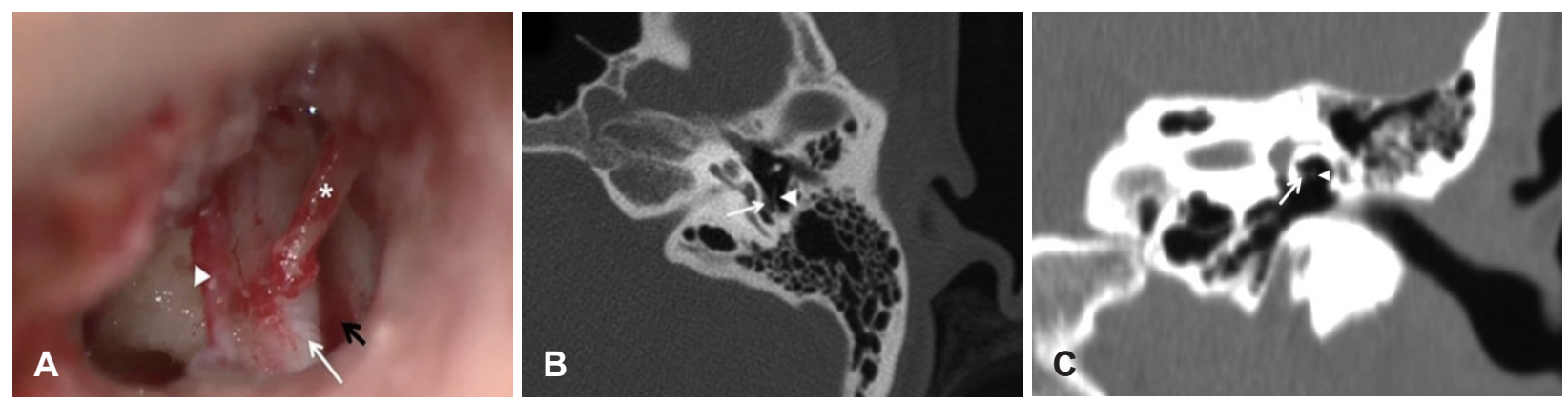

Fig. 2. Preoperative computed tomography (CT) of temporal bone. The tympanic segment of facial nerve (long arrows) runs inferomedially under the stapes (arrowheads). The oval window is not visible and the suprastructure of stapes is deformed. Axial view (A and B). Coronal view (C). 

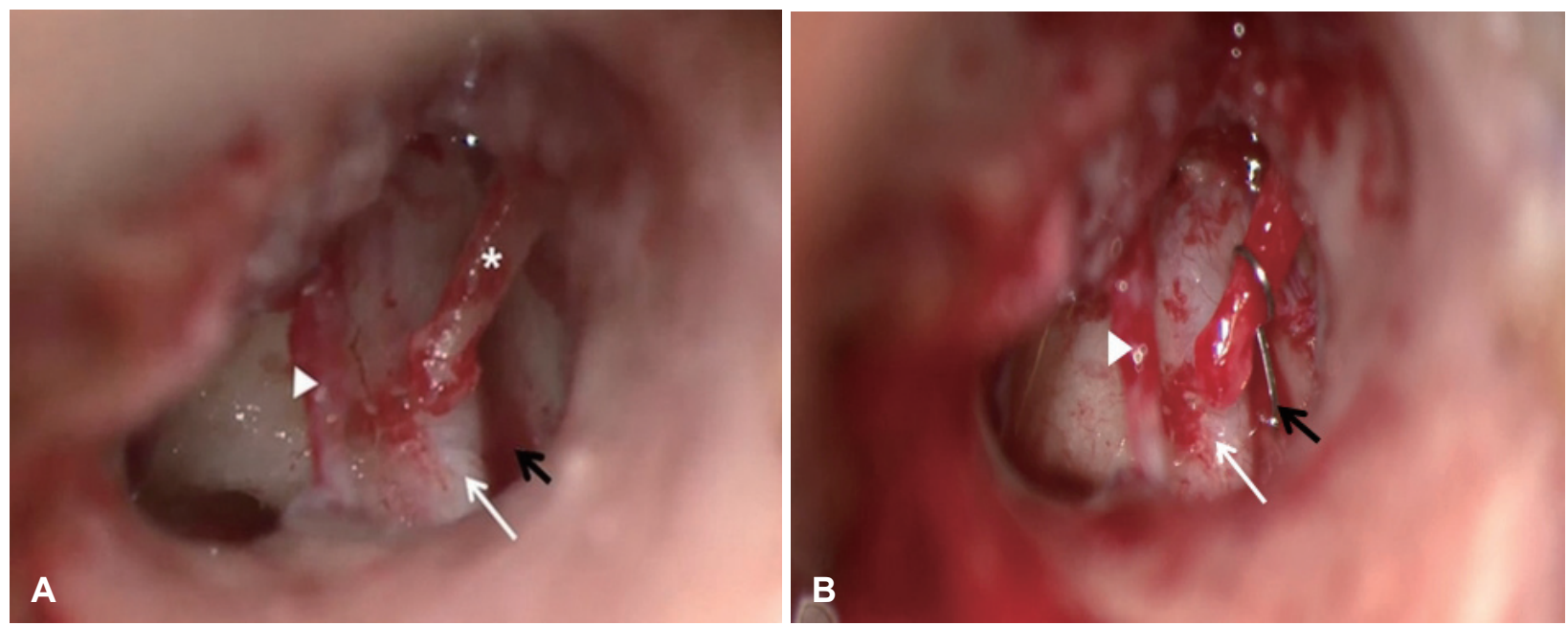

Fig. 3. Intraoperative microscope findings. After removal of the suprastructure of stapes. The tympanic segment of facial nerve (white arrow) ran inferomedially along the stapes. There was no oval window and just notch on vestibule (black arrow) (arrowhead: chorda tympani nerve, asterisk: long process of the incus) (A). Vestibulotomy was done to the notch on the vestibule above the facial nerve (white arrow). The piston wire (black arrow) above the facial nerve was anchored to long process of the incus. Chorda tympani nerve (arrowhead) was preserved (B).

\section{고 찰}

선천성 등골고정은 선천성 전음성 난청을 일으키는 흔한 원인으로, 주로 등골 족판 부위에 생기거나 등골 상부구조에 생겨 등골의 구조적 이상을 줄 수 있다. 선천성 등골고정 환자 에서 안면신경의 이상 주행을 보이는 경우는 드문 확률로 나 타나며, $\mathrm{An}$ 등 $^{2}$ 의 보고에 의하면 약 $11.2 \%$ 로 조사되었다. 발 생학적으로 살펴보면, 안면신경(facial nerve)은 제 2 새궁(second branchial arch) 및 이낭(otic capsule)에서 태생(gestational week) 4주부터 발생하여 태생 6주 초에 이미 측두골 내를 일 직선으로 주행하며, 등골 원기(stapes primordium)에 의하여 6주경에 후방으로 밀리면서 수직 및 수평 분절을 가지게 되 며, 이러한 주행은 태생 8 주경에 결정된다. ${ }^{2-4)}$ 제 2 새궁의 경 우 안면신경의 정상 주행 경로를 형성하는 데 중요한 영향을 주어, 제 2 새궁의 기형이 있을 경우 비정상적인 안면신경의 주 행을 유발한다. ${ }^{5)}$ 반면에 제 1 새궁이 불완전하게 발생될 경우 제2새궁의 보상적 오버쉬프트(overshifting)를 야기하여 안면 신경의 비정상적인 주행을 야기하기도 한다. ${ }^{6.7)}$ 안면신경 고실 분절의 비정상 주행은, 난원창(oval window)을 덮거나 등골 의 하방으로 주행하는 경로를 보이며, 난원창의 결손이나 이 형성 및 이소골들의 이형성을 동반하는 경우가 많다. ${ }^{8)}$ 그 이 유로, Lambert'는 발생과정 중 안면신경의 이상 주행이 발달 중인 등골과 이낭의 접촉을 막아 난원창 및 등골의 정상적인 발생을 막는 것으로 보고하였다. 이상 주행을 하는 안면신경 에 대한 분류를 살펴보면, Rohrt와 Lorentzen")은 중이 내에 서 비정상적 주행을 하는 안면신경을 안면신경이 부분적으로 등골족판을 없앤 것(obliteration), 안면신경이 분지한 것(bi- furcation), 안면신경이 등골 또는 난원창의 기형과 함께 등골 족판 위를 지나는 것, 안면신경이 고실갑각(promontory) 위를 지나는 것, 4 가지로 분류하였다.

등골수술(stapes surgery)은 전음성 난청의 수술적 치료법 중에서 난이도가 높고 부작용 발생 가능성이 비교적 높은 수 술이다. 본 증례와 같이 난원창의 결손 및 안면신경의 이상 주 행을 보이는 경우 안면신경 손상을 예방하고 청력을 개선하기 위해서는 전정 절개술(vestibulotomy) 및 수평반고리관 개창 술(fenestration of lateral semicircular canal)이 효과적인 대안 이 될 수 있다. ${ }^{10)}$ Sterkers와 Sterkers ${ }^{11)}$ 는 안면신경의 상방으로 전정계(scala vestibuli of the cochlear)를 통하여 효과적으로 수술을 시행하였으며, Yi 등른 수평반고리관(lateral semicircular canal)에 개창술을 시행하여 효과적인 청력개선을 얻 었다.

본 증례에서는 이상 주행을 하는 안면신경을 동반한 선천 성 등골고정 환자에서 전정 절개술을 시행하여, 안면신경 손 상 없이 수술 후 시행한 청력검사상 기도골도차가 약 $45 \mathrm{~dB}$ 정도 감소하는 효과적인 수술결과를 보였다. 등골수술을 시행 할 경우, 반드시 수술 전 전산화단층촬영을 면밀히 분석하여 안면신경의 이상 주행 여부, 이소골의 기형 및 난원창의 결손 여부 등을 확인하여 수술 중 합병증 없이 효과적으로 수술을 진행하여야 할 것이다.

\section{REFERENCES}

1) Shea JJ Jr. Forty years of stapes surgery. Am J Otol 1998;19(1):52-5.

2) An YS, Lee JH, Lee KS. Anomalous facial nerve in congenital stapes fixation. Otol Neurotol 2014;35(4):662-6.

3) Inagaki T, Kawano A, Ogawa Y, Shimizu M, Negishi M, Kawada Y, 
et al. Stapes fixation accompanied with abnormal facial nerve pathway. Auris Nasus Larynx 2014;41(3):313-6.

4) Martin C, Oletski A, Bertholon P, Prades JM. Abnormal facial nerve course associated with stapes fixation or oval window absence: report of two cases. Eur Arch Otorhinolaryngol 2006;263(1):79-85.

5) Jahrsdoerfer RA. Embryology of the facial nerve. Am J Otol 1988;9 (5):423-6.

6) Gerhardt HJ, Otto HD. The intratemporal course of the facial nerve and its influence on the development of the ossicular chain. Acta Otolaryngol 1981;91(5-6):567-73.

7) Lambert PR. Congenital absence of the oval window. Laryngoscope 1990;100(1):37-40.

8) Al-Mazrou KA, Alorainy IA, Al-Dousary SH, Richardson MA.
Facial nerve anomalies in association with congenital hearing loss. Int J Pediatr Otorhinolaryngol 2003;67(12):1347-53.

9) Rohrt T, Lorentzen P. Facial nerve displacement within the middle ear (report on 3 cases). J Laryngol Otol 1976;90(12):1093-8.

10) Pou JW. Congenital absence of the oval window. Report of two cases. Laryngoscope 1963;73:384-91.

11) Sterkers JM, Sterkers O. Surgical management of congenital absence of the oval window with malposition of the facial nerve. Adv Otorhinolaryngol 1988;40:33-7.

12) Yi Z, Yang J, Li Z, Zhou A, Lin Y. Bilateral congenital absence of stapes and oval window in 2 members of a family: etiology and management. Otolaryngol Head Neck Surg 2003;128(6):777-82. 